\title{
Sorption and Conformational Characteristics of Reconstituted Plant Cuticular Waxes on Montmorillonite
}

\author{
BAOLIANG CHEN AND BAOSHAN XING*
}

* Corresponding Author; E-mail Address: bx@pssci.umass.edu

Manuscript No.: ES050840j

Two Pages

One Figure 

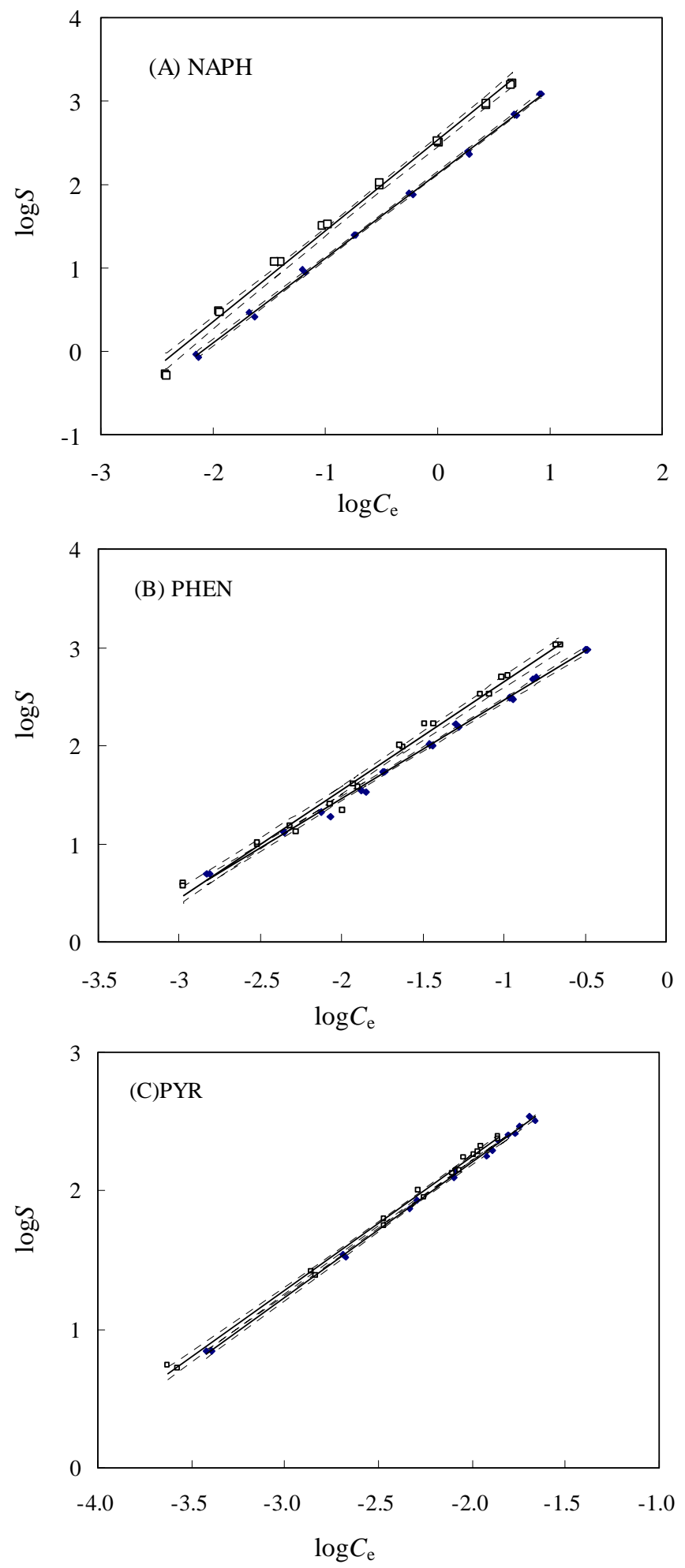

FIGURE S1. Isotherm confidence interval (95\%) and all of data points for NAPH (A), PHEN (B), and PYR (C) sorption ( $\square$ ) and desorption ( $\square$ ) by wax-mont 4. S: solid-phase concentration, $\mathrm{mg} / \mathrm{kg} ; C_{\mathrm{e}}$ : liquid-phase equilibrium concentration, $\mathrm{mg} / \mathrm{L}$. 